(3) Dr Woodcock's point about the effect of the failure rate had been considered. In any experimentation on human subjects missing data from subject loss tend to occur; there is no way of completely overcoming this problem, either clinically or statistically. We believe our analysis provided the most reasoned assessment of the data by (1) analysing between group failure rates and (2) analysing the existing data while explicitly acknowledging the possible effects of missing data. Furthermore both sets of data are presented and both show small positive effects for antimicrobials, so there is little chance of the reader being misled. At worst he may feel, as Dr Woodcock appears to, that we have shown that antimicrobials are effective.

BRENT TAYLOR

D FERguSSON

G D ABBotT

University of Otago Departmen of Paediatrics,

Christchurch Hospital,

Davis, S D, and Wedgwood, R J, American fournal of Diseases of Children, 1965, 109, 544

Gordon, M, Lovell, S, and Dugdale, A E, Medical

Fournal of Australia, 1974, 1, 304.

\section{Teaching general practice}

SIR,-While welcoming your promotion of general practice teaching in medical schools (22 October, p 1042) and agreeing that "academic investment should not be made conditional on service-earning capacity," I must take issue with you concerning "continuing genuine service role" for academic general practitioners.

Few would agree that in any aspect of lifeleast of all medicine - teaching can be divorced from practice. While all other departments in medical schools acknowledge the need for teachers to be clinically competent and active, let us not deny the same criteria to the developing teaching of primary care. Of course, clinical activity must not be maintained at the expense of providing teaching and research. But all three roles are essential to academic general practice. Sacrifice of the service role will be as damaging to the "academic general practitioner" as it would be to his hospital colleague.

GODFREY FOWLER

Oxford

\section{Indomethacin-induced asthma in aspirin-sensitive patients}

SIR, - We have recently had under our care a 43-year-old nursing sister with a two-year history of intrinsic asthma. She was known to be allergic to penicillin (rash) and aspirin (asthma). Her general practitioner prescribed indomethacin for musculoskeletal pains in her left leg. On 17 October at $5.30 \mathrm{pm}$ she took a $50-\mathrm{mg}$ capsule of indomethacin and within an hour started to wheeze. The bronchodilators she had at home (salbutamol inhaler and tablets and sodium cromoglycate) did not help her, so she called her general practitioner. On the GP's arrival at $8.15 \mathrm{pm}$ the patient was found to be extremely short of breath and two repeated subcutaneous doses of adrenaline were given together with 40 units of corticotrophin (ACTH). A little improvement followed and the patient was referred for hospital admission. On arrival at $9.10 \mathrm{pm}$ her peak flow rate was $170 \mathrm{l} / \mathrm{min}$. This improved to $200 \mathrm{l} / \mathrm{min}$ by $10.30 \mathrm{pm}$ after the patient had received a further $200 \mathrm{mg}$ of hydrocortisone intramuscularly and $4 \mathrm{mg}$ of salbutamol by mouth. She continued to improve overnight and by the next morning her chest was clear and peak flow rate was normal at $370 \mathrm{l} / \mathrm{min}$.

This case illustrates the potential dangers of prescribing indomethacin to patients known to have aspirin-induced asthma. This was first described by Vanselow and Smith. ${ }^{1}$ The nature of this cross-reactivity between indomethacin and aspirin is unknown; because of the dissimilar molecular structure it is unlikely to have an immunological basis and prior skin testing is known to be unhelpful. It is also important for doctors to remember that indomethacin is not the only analgesic which should be avoided in aspirin-sensitive asthmatics-paracetamol, mefenamic acid, and dextropropoxyphene are also known to induce asthma in this group of patients."

N MCI JOHNSON A E BLACK S W Clarke

Royal Free Hospital, 1 Vanselow, N A, and Smith, J R, Annals of Internal
Medicine, 1967, 66, 568.

Smith, A P, British Medical fournal, 1971, 2, 494.

\section{Pathogenesis of osteoarthrosis}

SIR,-Your leading article on this subject (15 October, p 979) makes no mention of the importance of joint laxity. Although congenital dislocation of the hip, ${ }^{1}$ recurrent dislocation of the patella, ${ }^{2}$ and familial hypermobility ${ }^{3}$ may all predispose to osteoarthrosis, attention has traditionally been directed towards repetitive impulsive loading. The most severe example of osteoarthrosis in a group of professional footballers occurred in one with abnormally lax ligaments. ${ }^{*}$ Assuming this to be related to collagen structure, which is inherited, rather than muscular hypotonia, which may be acquired, joint laxity, which has a Gaussian distribution throughout the population, ${ }^{5}$ may be a potent factor in the aetiology of osteoarthrosis. Moreover, this can be reconciled with Muir's explanation of the predisposition of some people to develop osteoarthrosis on the basis of inherited collagen structure.

H A BIRD

Rheumatism Research Unit, University of Leeds

Carter, C, and Wilkinson, J, fournal of Bone and foint Surgery, 1969, 46B, 40

Sutro, C J, Surgery, 1947, 21,67.

Beighton, P A, and Horan, F T, Fournal of Bone and foint Surgery, 1970, 52B, 145 .

Adams, I D, Clinics in Rheumatic Disease, 1976, 2, 523. Moll, J M H, and Wright, V, Annals of the Rheumatic Diseases, $1971,30,381$.

Muir, H, Annals of the Rheumatic Diseases, 1977. 36,

Training posts in medicine and allied specialties

SIR,-The Specialty Advisory Committees of the Joint Committee on Higher Medical Training (JCHMT) has been making steady progress in its task of inspection of senior registrar (or equivalent) training posts in medicine and allied specialties. Most of the posts put forward for corsideration have now been inspected and it is hoped that the remainder will be dealt with in the near future. Lists of posts approved for training after inspection are contained in the Second Report of the JCHMT and supplements thereto (available from the address below, price $£ 1.50$ ).

To assist applicants for a senior registrar post to determine its status in relation to JCHMT requirements the employing authorities have been requested to state in the advertisement for such a post that it has been approved (if this is the case) for training by the JCHMT. This is an additional safeguard to applicants who may not have access to a copy of the Second Report.

Applicants should note that the absence of a positive statement of approval in any advertisement does not necessarily mean that the post has been turned down by the JCHMT. It may be a perfectly satisfactory post that has not as yet been visited by an inspection team or it may be a post that has only minor training deficiencies which are in the course of being put right before final approval can be granted. However, the message to applicants is clear. If the advertisement does not include a positive statement of approval by the JCHMT they should in their own interests carefully scrutinise the further particulars of the post provided by the employing authority and, if necessary, pursue inquiries either before or at the interview to determine its training status.

R F ROBERTSON Joint Committee on Higher Medical Trainan, at the Royal College of Physicians of London 11 St Andrew's Place, Regent's Park,

\section{Report on first MASC meeting}

SIR,-Anyone reading your report (8 October, p 972) of the Conference of Academic Representatives held in Oxford on 26 September would be justified in concluding that the major problem confronting the newly established Medical Academic Staff Committee related solely to clinical academic staff-an impression reinforced by the space devoted (15 October, p 1037) to Dr Robert Lowe's discussion of the remuneration of clinical academic staff. Let there be no doubt that it is in the preclinical field where the most urgent problems lie: unless immediate action is taken to make the rewards of a career in the medical sciences comparable with those in other fields of medicine the effective medical component in many anatomy and physiology departments will have vanished within five years, and, as I write from an anatomy department, the medical science which has over the centuries proved itself concerned with the vocational relevance of teaching will have followed the pathway already taken by biochemistry.

Inquiry reveals that the reason for the failure to report the long deliberations concerning the preclinical problems was that the sole reporter assigned to the activity was available for either the clinical section meeting or the preclinical section meeting but that no way could be found to engage one reporter for each section meeting. The decision made instructing the reporter to cover the clinical debate is likely, therefore, to reflect the priorities of the BMA, which seems to be continuing to pay lip service only to concern for the critical position in preclinical departments while continuing to pursue policies that are 